\title{
Correction to: Differential Salt Sensitivity of Two Flax Cultivars Coincides with Differential Sodium Accumulation, Biosynthesis of Osmolytes and Antioxidant Enzyme Activities
}

\author{
Ahmad Mohammad M. Mekawy ${ }^{1} \cdot$ Dekoum V. M. Assaha $^{2} \cdot$ Akihiro Ueda $^{2,3}$ (D) \\ Published online: 23 June 2020 \\ ○) Springer Science+Business Media, LLC, part of Springer Nature 2020
}

\section{Correction to: Journal of Plant Growth Regulation https://doi.org/10.1007/s00344-019-10048-5}

The original version of this article unfortunately contained an error in figure legends. The figure legends were misplaced due to an editing error. While Figs. 2, 3, 4, and 5 were shown at the correct position, the figure legends should be rearranged as follows.

The original article has been corrected.

The original article can be found online at https://doi.org/10.1007/ s00344-019-10048-5.

Akihiro Ueda

akiueda@hiroshima-u.ac.jp

1 Department of Botany and Microbiology, Faculty of Science, Minia University, El-Minia 61519, Egypt

2 Graduate School of Biosphere Science, Hiroshima University, Higashi-Hiroshima 739-8528, Japan

3 Graduate School of Integrated Sciences for Life, Hiroshima University, Higashi-Hiroshima 739-8528, Japan 
Fig. 2 Effect of salt stress (150 $\mathrm{mM} \mathrm{NaCl}$ ) on the concentrations of a Proline and b Hydrogen peroxide in the leaf, stem, and root of the flax cultivars Sakha 102 and Sakha 105 after 21 days of treatment. Data represent the mean of 3 replicates $\pm \mathrm{SE}(n=3)$. The same letters indicate no significant differences $(P \leq 0.05)$

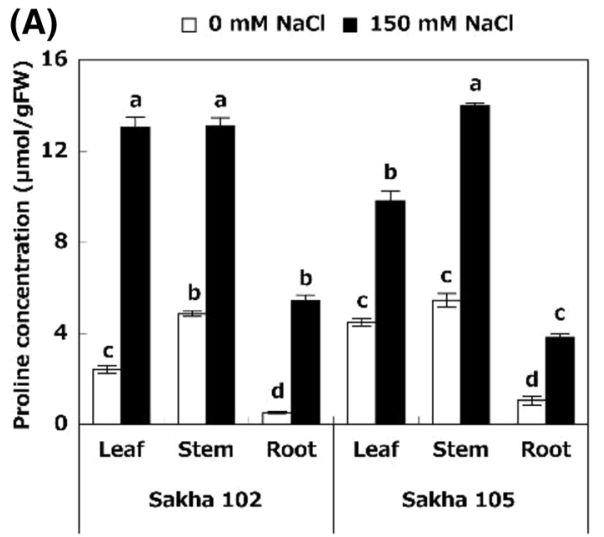

(B)

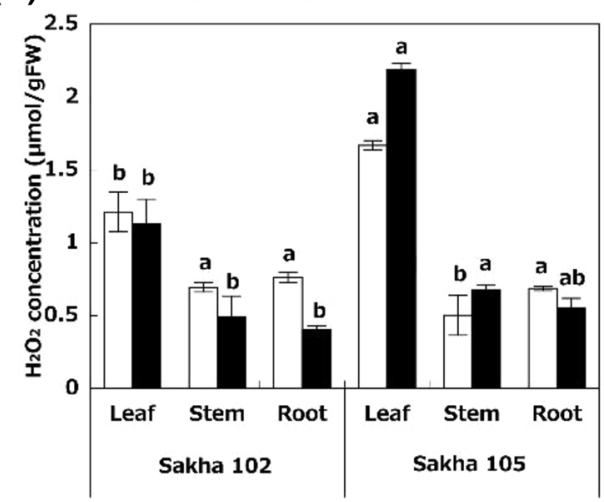

(C)

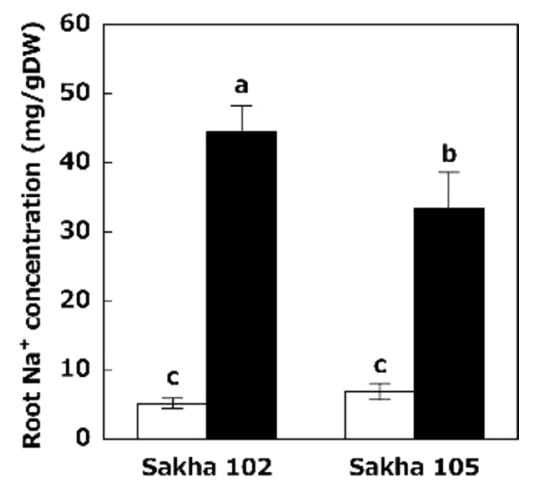

(B)

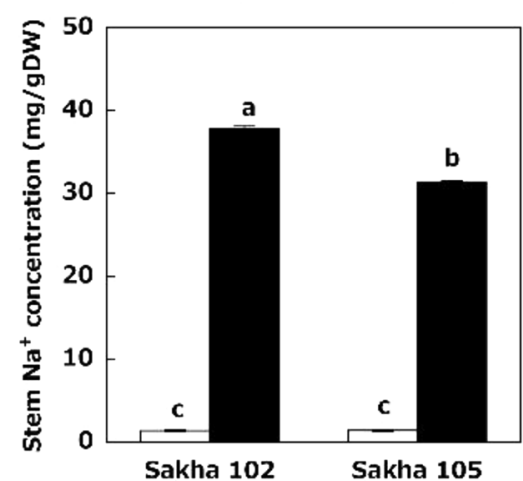

$\square 0 \mathrm{mM} \mathrm{NaCl} \square 150 \mathrm{mM} \mathrm{NaCl}$
(A)

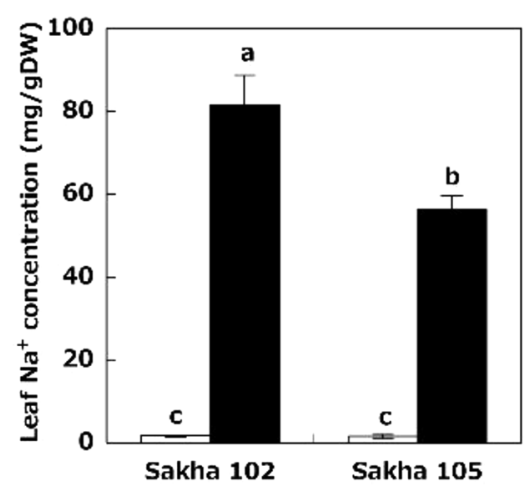


(A) $\quad \square \quad 0 \mathrm{mM} \mathrm{NaCl}=150 \mathrm{mM} \mathrm{NaCl}$

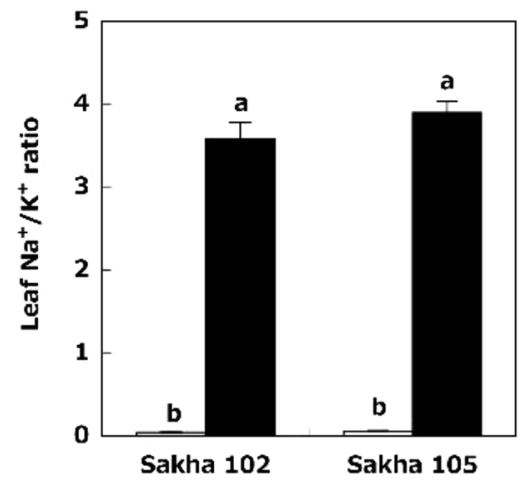

(B)

$0 \mathrm{mM} \mathrm{NaCl} \square 150 \mathrm{mM} \mathrm{NaCl}$

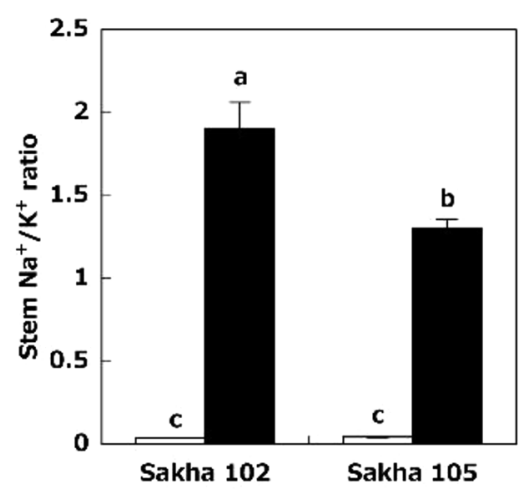

(C)

$\square 0 \mathrm{mM} \mathrm{NaCl}=150 \mathrm{mM} \mathrm{NaCl}$

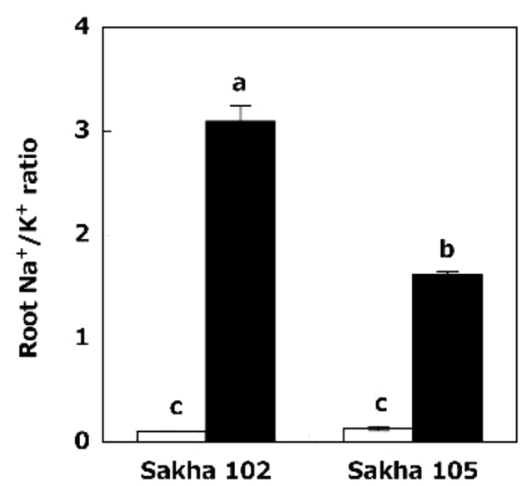

Fig. $5 \mathrm{Na}^{+} / \mathrm{K}^{+}$ratio in the a Leaf, $\mathbf{b}$ Stem and $\mathbf{c}$ Root of the flax cultivars Sakha 102 and Sakha 105 under control conditions and $150 \mathrm{mM}$ $\mathrm{NaCl}$ stress for 21 days of treatment. Data represent the mean of 3

Publisher's Note Springer Nature remains neutral with regard to jurisdictional claims in published maps and institutional affiliations. replicates $\pm \mathrm{SE}(n=3)$. The same letters indicate no significant differences $(P \leq 0.05)$ 